\title{
Flow-Induced Changes in Dimensions and Mechanical Properties of Rabbit Common Carotid Arteries*
}

\author{
Takeo MATSUMOTO ${ }^{* * * * *}$, Eijiro OKUMURA ${ }^{* * * * * *}$, Takahiro SHIRONO ${ }^{* * *}$, \\ Eiketsu $\mathrm{SHO}^{\dagger, \dagger \dagger}$, Hirotake MASUDA ${ }^{\dagger}$ and Masaaki SATO**
}

\begin{abstract}
Flow-induced changes in dimensions and mechanical properties of blood vessel wall were studied in the rabbit left common carotid arteries connected directly to the left external jugular vein via an arteriovenous fistula (AVF) to increase its blood flow by $>10$-fold for 4 weeks. Contralateral artery was used as control. We found significant increase not only in diameter, but also in thickness and length of unloaded artery exposed to increased flow, indicating the increase in wall volume. The increase in diameter and thickness but not in longitudinal length correlated significantly with the volumetric increase of the wall. Pressure-imposed test showed that the wall became less distensible in response to flow increase. Fluid shear stress estimated for physiological condition was significantly higher in AVF side than control, indicating that 10-fold increase in flow was not compensated in 4 weeks. Circumferential strain in a physiological pressure range was significantly lower in AVF side, while hoop stress was similar in both sides. These results may indicate that circumferential stress but not strain is maintained constant, and longitudinal change is not regulated in flow-imposed arteries.
\end{abstract}

Key Words: Biomechanics, Material Testing, Elasticity, Remodeling, Arteriovenous Fistula, Blood Vessel Wall, Stress/Strain Analysis

\section{Introduction}

Arteries are not simple elastic tubes. They change their dimensions and mechanical properties in response to mechanical stimulus such as intramural stress caused by the blood pressure and fluid shear stress caused by the blood flow. For example, hypertension causes increase in the thickness of the artery wall. This can be considered to be an adaptive response of the artery wall to maintain in vivo circumferential stress at a constant value against

* Received 20th June, 2005 (No. 05-4081)

** Biomechanics Laboratory, Graduate School of Mechanical Engineering, Tohoku University, 01 Aramaki-Aoba, Sendai, Miyagi 980-8579, Japan.

E-mail: takeo@nitech.ac.jp

*** Biomechanics Laboratory, Department of Mechanical Engineering, Nagoya Institute of Technology "Omohi” College, Gokiso-cho, Showa-ku, Nagoya 466-8555, Japan

**** Present affiliation: Nihon Kohden Corp., 1-31-4 NishiOchiai, Shinjuku-ku, Tokyo 161-0031, Japan

† Second Department of Pathology, Akita University School of Medicine, 1-1-1 Hondo, Akita 010-8543, Japan

$\dagger$ Present affiliation: Division of Vascular Surgery, Stanford University School of Medicine, Stanford, CA 943045450, USA the increase in the tension due to pressure elevation ${ }^{(1)-(3)}$. Inner diameter increases in the arteries adjacent to dialysis shunt (an arterio-venous shunt made in the arm or leg of the patients with renal failure as the blood access port for dialysis) ${ }^{(4)}$. Such increase in diameter may occur to restore the wall shear stress against the increase in the blood flow caused by the shunt ${ }^{(5),(6)}$.

The changes in the mechanical properties of arteries exposed to hypertension have been studied rather extensively ${ }^{(1)-(3),(7)-(9)}$. Other than wall thickening to maintain the in vivo stress at a constant level, decrease in both the inner diameter and the incremental elastic modulus over the normotensive pressure range, increase in the opening angle and in the longitudinal length of unloaded segments, etc. have been reported. Due to the decrease in the diameter and the elastic modulus of hypertensive subjects over the normotensive pressure range, their in vivo values, i.e., those in hypertensive pressure range were not significantly greater than in vivo values of the normotensive subjects. These changes have been pointed out to be adaptive responses of artery wall to maintain the wall shear stress and the material elasticity of the wall in preset ranges. The increase in the opening angle may also be an adaptive change of the arterial wall to maintain the stress concen- 
tration factor at a constant value ${ }^{(8)}$. On the contrary, the increase in the unloaded length of the arterial segments might be an indirect response of the wall thickening: Arterial wall volume may increase not only in the radial direction, i.e., wall thickening, but also in the longitudinal direction, because medial smooth muscle cells are preferably oriented in the circumferential direction and their hypertrophy or increase in their diameter may increase the volume both in the radial and axial directions ${ }^{(8)}$.

With regard to the mechanical properties of the arteries exposed to the increase in blod flow, however, there are not many studies. In a conference proceedings, Makino et al. reported that the mechanical properties of rat carotid arteries exposed to increased flow for 8 weeks were almost similar to those of controls ${ }^{(10)}$. They increased blood flow by ligating the contralateral artery, and the increase was less than $50 \%$ of control value. Considering that the cardiac output generally increase by several-fold in response to severe exercise, the amount of increase in blood flow used in their study was not satisfactory to study flowinduced responses.

In this study, we made an arteriovenous fistula (AVF) between the common carotid artery and the external jugular vein of rabbits to increase the blood flow by more than 10 -fold in the carotid arteries for 4 weeks, and observed the changes in the dimensions and mechanical properties of the arteries in response to flow increase. We found significant increase not only in diameter, but also in thickness and length of unloaded artery segments exposed to increased flow. The wall also became stiffer in response to flow increase. We also examined whether the volumetric increase of the wall was anisotropic to find that the increase in the longitudinal volume had poor correlation with total volumetric increase.

\section{Materials and Methods}

\subsection{Specimen}

Common carotid arteries (CCA) of adult, male, Japanese white rabbits weighing 3.0 to $4.0 \mathrm{~kg}$ were used as the test model. AVFs were made on the left CCAs of 6 rabbits (shunt group). Their untreated right CCAs were used as the control. To obtain mechanical properties and dimensions in normal animals, we also used the left CCAs obtained from 9 nonoperated rabbits (normal group). All subsequent animal experiments and treatments were conducted in accordance with the Guidelines for Animal Experimentation of Akita University and Tohoku University.

\subsection{Arteriovenous fistula operation}

Details have been reported elsewhere ${ }^{(6)}$. Briefly, animals were anesthetized by inhalation anesthesia of Sevoflurane. Both common carotid arteries and the left jugular vein were exposed under sterile condition. After clamping of the left common carotid artery and left jugular vein, a 5-mm longitudinal incision was made in the left common carotid artery $10 \mathrm{~mm}$ distal to the thyroid branch and in the left jugular vein at the same level. Heparinized saline was instilled locally, and an AVF was created by anastomosis of the two vessels with a continuous 8-0 nylon suture. Blood flow rate of the left and right common carotid arteries was measured before construction of the AVF and 10 minutes after completion of the AVF by using an electromagnetic flowmeter (Nihon Kohden Co).

\subsection{Specimen excision}

Four weeks after the operation, the animals were anesthetized with pentobarbital sodium $(\sim 25 \mathrm{mg} / \mathrm{kg})$, and the CCAs were carefully exposed. The artery was marked with the suture to identify its in vivo length. Blood flow was measured as during the AVF operation. We also tried to measure blood pressure via catheter, but measured values were not reproducible under the anesthesia with pentobarbital. Referring to a precise blood pressure measurement of Japanese white rabbits under conscious condition $^{(11)}$, mean blood pressure was taken as $80 \mathrm{mmHg}$ for normal animals. It has been reported that mean blood pressure of rabbits with AVF was not significantly different from unoperated animals ${ }^{(6)}$. Thus, mean blood pressure of operated animals was also taken as $80 \mathrm{mmHg}$. Animals were then killed by injection of an overdose of pentobarbital sodium $(100 \mathrm{mg} / \mathrm{kg})$ and $20-30 \mathrm{~mm}$ long tubular segments of the left and right CCAs were excised. With regard to normal group, the CCAs were marked and excised after animals were killed by the overdose of the pentobarbital sodium without measuring blood flow. All the specimens were kept in a physiological saline solution at $4^{\circ} \mathrm{C}$ until the measurements performed within 24 hours postmortem.

\subsection{Mechanical testing}

The experimental setup used for the mechanical testing is similar to that used by Matsumoto et al. ${ }^{(12)}$ Briefly, the tubular segment obtained from the CCA was attached to a jig and stretched to its in vivo length referring the markings on its surface in a tissue bath filled with the physiological saline at room temperature. It was then distended and collapsed with the saline changing the intraluminal pressure between 0 and $200 \mathrm{mmHg}$ at a rate of about $3 \mathrm{mmHg} / \mathrm{sec}$. The outer diameter $D_{o}$ was measured with a video dimension analyzer (E-1000, Elcow, Hakodate, Japan), and the intraluminal pressure $P_{i}$ with a pressure transducer. The distension and collapse were repeated 5 to 8 times until the pressure-diameter (P-D) loop became reproducible. The ascending limb of the last stable loop was used for the data analysis.

\subsection{Dimension measurement}

After these mechanical tests, the vessel was removed from the apparatus and a thin ring specimen was sliced out with scissors from the portion where the external diameter was measured during testing. The internal and external diameters of the sliced ring ( $d_{i}$ and $d_{o}$, respectively) 
were measured in the saline at room temperature with a low magnification microscope. The internal diameter at $P_{i}, D_{i}\left(P_{i}\right)$, was calculated assuming the incompressibility of the wall material:

$$
D_{i}\left(P_{i}\right)=\sqrt{\left(D_{o}\left(P_{i}\right)\right)^{2}-\frac{1}{\lambda_{z}}\left(d_{o}^{2}-d_{i}^{2}\right)}
$$

where $D_{o}\left(P_{i}\right)$ is the outer diameter at $P_{i}$, and $\lambda_{z}$ is the axial stretch ratio which is the ratio of the vascular length in the in vivo state $L$ to that in the state at no load $l$.

\subsection{Calculation of mechanical parameters}

Mechanical properties of the specimens were evaluated with parameters relevant to stiffness and inherent elastic properties of the artery wall as well as their circumferential stress-strain relationships at in vivo longitudinal length, all of which were derived from the P-D curves.

Apparent stiffness was evaluated with the pressurestrain elastic modulus $E_{P}\left(P_{i}\right)^{(13)}$ given by:

$$
E_{p}\left(P_{i}\right)=\frac{\Delta P_{i}}{\Delta D_{o} / D_{o}\left(P_{i}\right)}
$$

where $\Delta P_{i} / \Delta D_{o}$ is the slope of the P-D curve at $P_{i}$. To represent the inherent elastic properties of wall material, the incremental elastic modulus $H_{p}\left(P_{i}\right)$ introduced by Hudetz $^{(14)}$ for orthotropic material was used:

$$
\begin{aligned}
H_{p}\left(P_{i}\right)= & 2\left\{\frac{\Delta P_{i}}{\Delta D_{o}} \frac{D_{o}\left(P_{i}\right)\left(D_{i}\left(P_{i}\right)\right)^{2}}{\left(D_{o}\left(P_{i}\right)\right)^{2}-\left(D_{i}\left(P_{i}\right)\right)^{2}}\right. \\
& \left.+\frac{P_{i}\left(D_{o}\left(P_{i}\right)\right)^{2}}{\left\{D_{o}\left(P_{i}\right)\right\}^{2}-\left(D_{i}\left(P_{i}\right)\right)^{2}}\right\} .
\end{aligned}
$$

Generally speaking, carotid arteries are distensible in a low pressure region and become abruptly stiff over a certain point. We call this point a bending point and defined it as the intersection of two tangents to the P-D curve at 20 and $180 \mathrm{mmHg}^{(15)}$. To estimate the pressure at transition from the distensible part to stiff part, we also obtained the pressure at bending point $P_{b}$.

Circumferential stress $\sigma_{\theta}$ was calculated by the law of Laplace:

$$
\sigma_{\theta}\left(P_{i}\right)=\frac{P_{i} D_{i}\left(P_{i}\right)}{2 H\left(P_{i}\right)},
$$

where $H\left(P_{i}\right)$ is wall thickness at $P_{i}$. Circumferential stretch ratio $\lambda_{\theta}\left(P_{i}\right)$ was obtained as follows:

$$
\lambda_{\theta}\left(P_{i}\right)=\frac{D_{o}\left(P_{i}\right)+D_{i}\left(P_{i}\right)}{D_{o}(0)+D_{i}(0)} .
$$

In addition to parameters on elastic properties of the artery wall, fluid dynamic shear stress $\tau_{w}\left(P_{i}\right)$ caused by the intraluminal blood flow was obtained assuming Poiseuille flow from $D_{i}\left(P_{i}\right)$ and the flow rate $Q$ measured just before specimen excision:

$$
\tau_{w}\left(P_{i}\right)=\frac{4 Q \eta}{\pi\left(D_{i}\left(P_{i}\right) / 2\right)^{3}},
$$

where $\eta$ is the viscosity of blood and was taken as $4 \mathrm{mPa}$ s. For specimens in normal group whose flow rate was not measured, we used mean flow rate of unoperated animals $^{(6)}$.

These parameters were calculated for every $10 \mathrm{mmHg}$ of $P_{i}$.

\subsection{Analysis of the volumetric changes of the wall}

Change in the wall volume was examined in the unloaded segments having a unit length in situ. The mean circumferential length $\pi d_{m}=\pi\left(d_{i}+d_{o}\right) / 2$, radial length or thickness $h$, and longitudinal length $l=1 / \lambda_{z}$ were obtained in the shunt and control specimens. Wall volume $v$ was calculated by:

$$
v=\frac{\pi\left(d_{i}+d_{o}\right) h}{2 \lambda_{z}}=\pi d_{m} h l .
$$

The ratio of each parameter in the shunt specimens to that in the control was calculated for each animal and used as the index of dimensional or volumetric changes in the segments.

\subsection{Statistical analysis}

Data are expressed as mean \pm SEM. Differences were analyzed by the Student's paired and unpaired t-test, and were considered significant when $P<0.05$.

\section{Results}

Data obtained in the present study are summarized in Table 1 for three groups. Hemodynamic parameters, dimensions, and mechanical properties of the arterial segments in loaded states are shown every $40 \mathrm{mmHg}$ of intraluminal pressure. Blood flow $Q$ increased stepwise by a factor of 3.5 following the AVF operation and then continued to increase by a factor of 18.5 in 4 weeks (Shunt). No significant change was observed in the flow in the contralateral side (Control). These results were quantitatively similar to the previous study ${ }^{(6)}$. With regard to the normal group in which blood flow was not measured, mean blood flow rate in unoperated rabbits ${ }^{(6)}$ was used to calculate wall shear stress. Wall shear stress $\tau_{w}$ was significantly higher in the shunt group than the control and normal groups at all pressures examined. In response to the increase in wall shear stress, the decrease in the longitudinal stretch ratio $\lambda_{z}$, the increase in the blood vessel diameters $d_{o}, d_{i}, d_{m}$, and $D_{i}$ and wall thicknesses $h$ and $H$ was significant in the shunt group. So was the wall volume $v$. There were no significant differences between the control and normal groups in these parameters.

Figure 1 shows the P-D curves in the three groups. Outer diameter was significantly larger in the shunt group than both of the control and normal groups $(P<0.001)$ in the entire pressure range, indicating the flow-induced enlargement. The diameter was also significantly larger $(P<0.05)$ in the control group than in the normal. This might be attributable to the difference in the body weight between the shunt/control group and the normal group (Table 1). With regard to arterial stiffness, $E_{p}$ was statistically similar among the three groups except in the 
Table 1 Summary of dimensions and mechanical properties of rabbit common carotid arteries

\begin{tabular}{|c|c|c|c|}
\hline Parameters & Shunt (LCCA) & Control (RCCA) & Normal (LCCA) \\
\hline$n$ & 6 & 6 & 9 \\
\hline BW (kg) & $3.6 \pm 0.1^{\dagger}$ & $3.6 \pm 0.1^{\dagger}$ & $3.2 \pm 0.1$ \\
\hline$\lambda_{\mathrm{z}}$ & $1.382 \pm 0.071^{*, \dagger}$ & $1.581 \pm 0.052$ & $1.672 \pm 0.048$ \\
\hline$P_{\mathrm{b}}(\mathrm{mmHg})$ & $42 \pm 3^{* *, \dagger}$ & $63 \pm 4$ & $55 \pm 4$ \\
\hline \multicolumn{4}{|l|}{ Flow rate $Q(\mathrm{ml} / \mathrm{min})$} \\
\hline Before operation & $16.4 \pm 0.4$ & $19.4 \pm 1.6$ & $(19.4)^{1}$ \\
\hline After operation & $58.5 \pm 3.9^{* *}$ & $22.4 \pm 1.0$ &.- \\
\hline $4 \mathrm{w}$ after $\mathrm{AFV}$ & $303.9 \pm 49.8^{* *}$ & $20.9 \pm 0.8$ & - - - \\
\hline \multicolumn{4}{|l|}{ Parameters at no load } \\
\hline$d_{\mathrm{o}}(\mathrm{mm})$ & $2.760 \pm 0.085^{* *, \dagger \dagger}$ & $1.968 \pm 0.049$ & $1.980 \pm 0.051$ \\
\hline$d_{\mathrm{i}}(\mathrm{mm})$ & $1.784 \pm 0.054^{* *, \dagger \dagger}$ & $1.204 \pm 0.045$ & $1.242 \pm 0.031$ \\
\hline$d_{\mathrm{m}}(\mathrm{mm})\left[=\left(d_{0}+d_{\mathrm{i}}\right) / 2\right]$ & $2.272 \pm 0.059^{* *, 4 \dagger}$ & $1.586 \pm 0.044$ & $1.611 \pm 0.038$ \\
\hline$h(\mathrm{~mm})$ & $0.488 \pm 0.040^{*, \dagger}$ & $0.382 \pm 0.017$ & $0.369 \pm 0.024$ \\
\hline$l(\mathrm{~mm} / \mathrm{mm})\left[=1 / \lambda_{\mathrm{z}}\right]$ & $0.735 \pm 0.046^{*, \dagger}$ & $0.636 \pm 0.022$ & $0.602 \pm 0.017$ \\
\hline$v\left(\mathrm{~mm}^{3} / \mathrm{mm}\right)$ & $2.513 \pm 0.162^{* *, \dagger \dagger}$ & $1.211 \pm 0.076$ & $1.133 \pm 0.103$ \\
\hline \multicolumn{4}{|l|}{ Parameters at $P_{\mathrm{i}}=40 \mathrm{mmHg}$} \\
\hline$D_{\mathrm{i}}(\mathrm{mm})$ & $3.383 \pm 0.085^{* *,\rangle^{*} \dagger}$ & $2.206 \pm 0.115^{\dagger}$ & $1.859 \pm 0.066$ \\
\hline$H(\mathrm{~mm})$ & $0.218 \pm 0.011^{* *}$ & $0.165 \pm 0.006$ & $0.179 \pm 0.016$ \\
\hline$\tau_{\mathrm{w}}(\mathrm{Pa})$ & $5.33 \pm 0.79^{* *, \dagger \dagger}$ & $1.43 \pm 0.21$ & $2.05 \pm 0.23$ \\
\hline$\sigma_{\theta}(\mathrm{kPa})$ & $41.7 \pm 1.5^{*}$ & $35.7 \pm 2.0$ & $31.9 \pm 5.8$ \\
\hline$\lambda_{\theta}$ & $1.523 \pm 0.046^{\dagger}$ & $1.626 \pm 0.044$ & $1.723 \pm 0.062$ \\
\hline$E_{\mathrm{p}}(\mathrm{kPa})$ & $38.3 \pm 6.6^{*}, \dagger$ & $19.2 \pm 0.9$ & $21.5 \pm 2.3$ \\
\hline$H_{\mathrm{p}}(\mathrm{kPa})$ & $334 \pm 56^{*, \dagger \dagger}$ & $165 \pm 13$ & $151 \pm 23$ \\
\hline \multicolumn{4}{|l|}{ Parameters at $P_{\mathrm{i}}=80 \mathrm{mmHg}$} \\
\hline$D_{\mathrm{i}}(\mathrm{mm})$ & $3.703 \pm 0.090^{* *,+\dagger}$ & $2.671 \pm 0.097^{\dagger}$ & $2.237 \pm 0.111$ \\
\hline$H(\mathrm{~mm})$ & $0.201 \pm 0.010^{* *, \dagger}$ & $0.139 \pm 0.006$ & $0.155 \pm 0.015$ \\
\hline$\tau_{\mathrm{w}}(\mathrm{Pa})$ & $4.02 \pm 0.55^{* *, \dagger \dagger}$ & $0.78 \pm 0.09$ & $1.28 \pm 0.20$ \\
\hline$\sigma_{\theta}(\mathrm{kPa})$ & $99.0 \pm 4.2$ & $102.9 \pm 5.1$ & $91.1 \pm 17.8$ \\
\hline$\lambda_{\theta}$ & $1.652 \pm 0.052^{*, \dagger}$ & $1.936 \pm 0.082$ & $2.027 \pm 0.094$ \\
\hline$E_{\mathrm{p}}(\mathrm{kPa})$ & $159.2 \pm 16.4^{* *}$ & $89.8 \pm 12.7$ & $149.9 \pm 26.5$ \\
\hline$H_{\mathrm{p}}(\mathrm{kPa})$ & $1497 \pm 110^{* *}$ & $934 \pm 115$ & $1110 \pm 154$ \\
\hline \multicolumn{4}{|l|}{ Parameters at $P_{\mathrm{i}}=120 \mathrm{mmHg}$} \\
\hline$D_{\mathrm{i}}(\mathrm{mm})$ & $3.801 \pm 0.086^{* *, \dagger \dagger}$ & $2.791 \pm 0.098^{\dagger}$ & $2.306 \pm 0.119$ \\
\hline$H(\mathrm{~mm})$ & $0.196 \pm 0.011^{* *, \dagger}$ & $0.134 \pm 0.006$ & $0.151 \pm 0.014$ \\
\hline$\tau_{\mathrm{w}}(\mathrm{Pa})$ & $3.72 \pm 0.52^{* *,+\dagger}$ & $0.68 \pm 0.08$ & $1.18 \pm 0.20$ \\
\hline$\sigma_{\theta}(\mathrm{kPa})$ & $156.4 \pm 7.2$ & $168.2 \pm 9.3$ & $144.9 \pm 28.8$ \\
\hline$\lambda_{\theta}$ & $1.691 \pm 0.052^{*, \dagger}$ & $2.017 \pm 0.093$ & $2.072 \pm 0.100$ \\
\hline$E_{\mathrm{p}}(\mathrm{kPa})$ & $441.9 \pm 72.3^{*}$ & $275.1 \pm 16.4^{\dagger}$ & $423.1 \pm 40.0$ \\
\hline$H_{\mathrm{p}}(\mathrm{kPa})$ & $4202 \pm 608$ & $2955 \pm 221$ & $3467 \pm 510$ \\
\hline \multicolumn{4}{|l|}{ Parameters at $P_{\mathrm{i}}=160 \mathrm{mmHg}$} \\
\hline$D_{\mathrm{i}}(\mathrm{mm})$ & $3.849 \pm 0.082^{* *, \dagger \dagger}$ & $2.837 \pm 0.100^{\dagger}$ & $2.338 \pm 0.121$ \\
\hline$H(\mathrm{~mm})$ & $0.194 \pm 0.011^{* *, \dagger}$ & $0.132 \pm 0.006$ & $0.149 \pm 0.014$ \\
\hline$\tau_{\mathrm{w}}(\mathrm{Pa})$ & $3.60 \pm 0.52^{* *, \dagger \dagger}$ & $0.65 \pm 0.08$ & $1.13 \pm 0.19$ \\
\hline$\sigma_{\theta}(\mathrm{kPa})$ & $213.7 \pm 10.7$ & $231.2 \pm 12.2$ & $198.3 \pm 39.5$ \\
\hline$\lambda_{\theta}$ & $1.711 \pm 0.052^{*, \dagger}$ & $2.047 \pm 0.093$ & $2.097 \pm 0.102$ \\
\hline$E_{\mathrm{p}}(\mathrm{kPa})$ & $1066.3 \pm 297.8$ & $673.1 \pm 150.6$ & $711.3 \pm 76.2$ \\
\hline$H_{\mathrm{p}}(\mathrm{kPa})$ & $10216 \pm 2895$ & $7616 \pm 2183$ & $6469 \pm 1324$ \\
\hline
\end{tabular}

L/RCCA, left/right common carotid artery; AVF, arteriovenous fistula; $\mathrm{BW}$, body weight; $\lambda_{\mathrm{z}}$, longitudinal stretch ratio; $P_{\mathrm{b}}$, pressure at bending point; $P_{\mathrm{i}}$, intraluminal pressure; $d_{0}$, outer diameter; $d_{\mathrm{i}}$ and $D_{\mathrm{i}}$, inner diameter; $d_{\mathrm{m}}$, mean diameter; $h$ and $H$, wall thickness; $l$, no load length of a segment with a unit length in situ; $v$, wall volume of a segment with a unit length in situ; $\tau_{\mathrm{w}}$, wall shear stress; $\sigma_{\theta}$, hoop stress; $\lambda_{\theta}$, circumferential stretch ratio; $E_{\mathrm{p}}$, pressure-strain elastic modulus; $H_{\mathrm{p}}$, incremental elastic modulus. ${ }^{*} P<0.05,{ }^{* *} P<0.01$ vs Control; ${ }^{\dagger} P$ $<0.05,{ }^{\dagger \dagger} P<0.01 v s$ Normal. ${ }^{1}$ Flow rate in unoperated animal ${ }^{(6)}$. Wall shear stress of Normal was calculated based on this value.

pressure range between $30-130 \mathrm{mmHg}$ (Table 1). $E_{p}$ was significantly higher in the shunt group than in the control in the pressure range between $30-120 \mathrm{mmHg}$. It was also higher in the control group than in the normal group in the pressure range between $90-130 \mathrm{mmHg}$. The pressure at bending point $P_{b}$ was significantly lower in the shunt group than in the other two groups. Taken together, P-D curves of the shunt group showed not only flowinduced enlargement but also lowering of the pressure at the bending point, while maintaining their slope at low $(<30 \mathrm{mmHg})$ and high $(>120 \mathrm{mmHg})$ pressure regions unchanged. These changes indicate that the artery walls in the shunt group become less distensible.

Stress-strain relationships of the wall in the circum- ferential direction were obtained at its in vivo longitudinal length from the P-D curves (Fig. 2). Corresponding to the changes in the P-D curves, the artery walls were less distensible in the shunt group than in the other two groups. Strain (stretch ratio, in this case) was significantly smaller in the shunt group than in the control and normal groups over $50 \mathrm{mmHg}$. Contrary to P-D curves, there was no significant difference in stress and strain between the control and normal groups at the same pressure level. With regard to elastic modulus, $H_{p}$ was significantly higher in the shunt group than in the control in the pressure range between $20-110 \mathrm{mmHg}$ (Table 1). Similarly, it was significantly higher in the shunt group than in the normal in the pressure range between $20-70 \mathrm{mmHg}$. The incremen- 


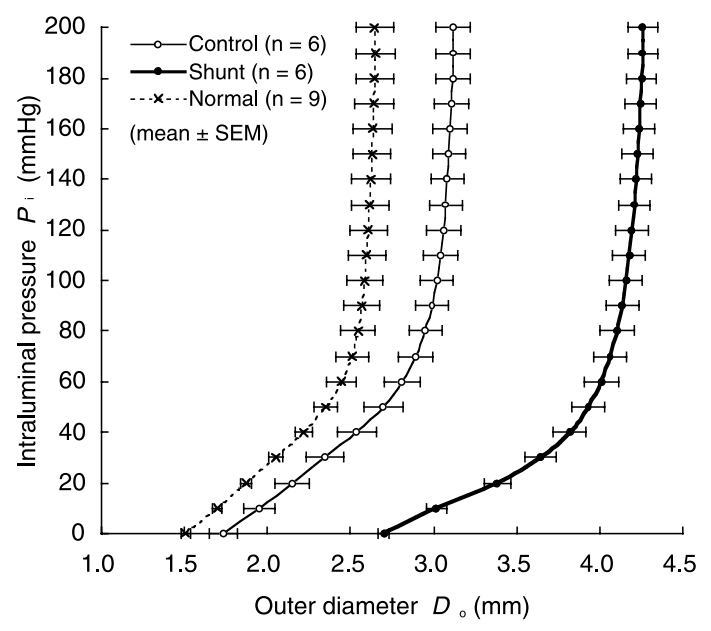

Fig. 1 Pressure-diameter curves of shunt, control, and normal specimens. Control and shunt specimens were obtained from the right and left common carotid arteries, respectively, of the same rabbit

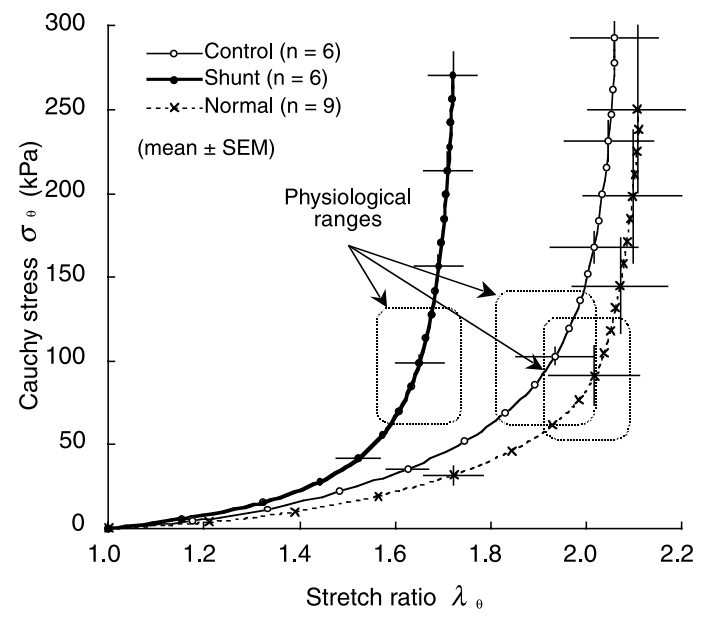

Fig. 2 Stress-stretch ratio curves of shunt, control, and normal specimens. Although data points are shown every $10 \mathrm{mmHg}$, error bars were shown every $40 \mathrm{mmHg}$ for clarity. Points within the physiological pressure range $(60-100 \mathrm{mmHg})$ are enclosed with dotted lines

tal elastic modulus was statistically similar between the control and normal groups at all pressures. It has been reported that mean blood pressure of rabbits with AVF was not significantly different from unoperated animals ${ }^{(6)}$, and that the mean blood pressure of Japanese white rabbits under conscious condition was $80 \mathrm{mmHg}^{(11)}$. Based on these reports, physiological range was indicated in each curves. The strain in the physiological condition was significantly smaller in the shunt group than in the other two groups, while the stress was almost similar among the groups (Table 1).

Dimensional changes were anisotropic. Wall volume doubled in response to the increase in the blood flow $(v$ in Table 1), while circumferential $\left(d_{m}\right)$, radial $(h)$, and longitudinal $(l)$ dimensions in the unloaded segment in-

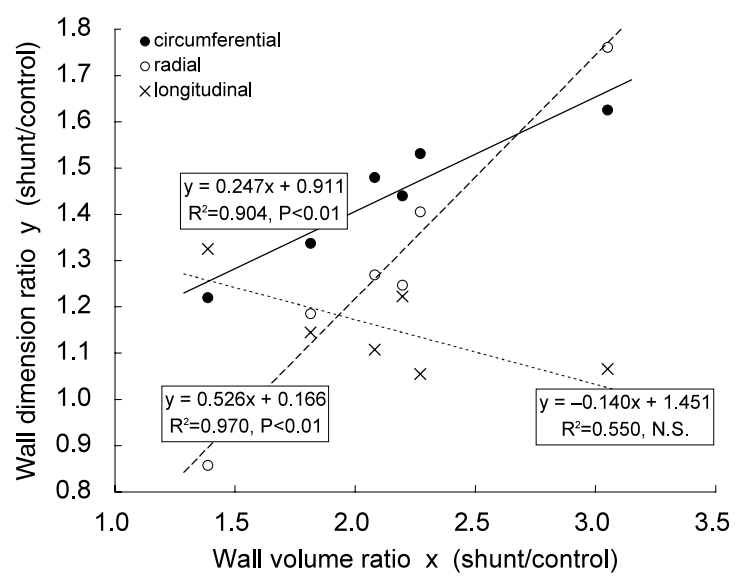

Fig. 3 Relationships between change in wall volume and changes in circumferential, radial, and longitudinal lengths in unloaded specimens. No load dimensions, i.e., mean circumference $\pi\left(d_{i}+d_{o}\right) / 2$, thickness $h$, and longitudinal length $l$ of each of the shunt specimens were divided by corresponding dimensions of its contralateral counterpart and plotted against the ratio of wall volume of the shunt specimens to the control for each animal

creased by $\sim 40 \%, \sim 30 \%$, and $\sim 15 \%$, respectively. The anisotropy became more prominent when the relationships among the flow-induced changes in these parameters were analyzed (Fig. 3). The shunt/control ratio of the circumferential and radial dimensions had significant positive correlation with that of the wall volume, while the correlation was negative and insignificant for the longitudinal dimension.

\section{Discussion}

\subsection{Flow-induced changes in artery dimensions}

One of the most remarkable changes of the artery induced with the increase in blood flow would be enlargement of vessel diameter, which has been considered to be an adaptive response of blood vessel wall to maintain wall shear stress in a physiological range. Vessel diameter also increased in this study. Wall shear stress was, however, remained much higher than the normal value (Table 1). Masuda et al. ${ }^{(6)}$ reported that wall shear stress of rabbit carotid artery went over $10 \mathrm{kPa} 3$ days after AVF operation, then gradually decreased, and remained higher $(3.7 \mathrm{kPa})$ than the normal value $(1.2 \mathrm{kPa})$ even 8 weeks after the operation. Kamiya and Togawa ${ }^{(5)}$ reported in canine carotid arteries that wall shear stress did not return to the normal level even after 8 months if the increase in blood flow rate was more than 4 times. Although the artery walls responded adaptively in the present study, it may fail to compensate the shear stress increase because the flow increase was more than 10 times.

As Laplace's law describes, hoop stress increases in response to the increase in artery diameter even if blood pressure remains unchanged. It has been pointed out that 
artery walls adaptively maintain their in vivo hoop stress within a physiological range by increasing their thickness against hypertension ${ }^{(1)-(3)}$. The wall thickening occurred very fast so as to maintain the hoop stress almost unchanged during the pressure elevation phase following the induction of Goldblatt hypertension ${ }^{(3)}$. In this study, the wall was significantly thicker in the shunt group and hoop stress did not differ significantly among the three groups (Table 1), indicating that the adaptation process to maintain hoop stress within a physiological range took place also in flow-induced environment. It is also suggested that this process was much more active than that to maintain wall shear stress within a physiological range.

\subsection{Flow-induced changes in mechanical proper- ties of the artery}

Artery wall became less distensible in the shunt group as indicated by the lowering of $P_{b}$ (Table 1) and the decrease in the strain in physiological range (Fig. 2). Lowering of $P_{b}$ indicates decrease in the slack length of collagen fibers in the wall ${ }^{(15)}$, i.e., more collagen fibers become stretched in a physiological state in the arteries with lower $P_{b}$. This may explain the increase in $E_{p}$ and $H_{p}$ in the shunt group in the physiological state, because more collagen fibers that are several order of magnitude stiffer than elastin and smooth muscle cells ${ }^{(16)}$ will be stretched in this group. The decrease in the physiological strain may be caused by the decrease in the elastic recoil of the unloaded wall, i.e., the increase in the unstressed length of the wall due to the increase in wall volume (Table 1). The increase in the unstressed length should be much larger in smooth muscle and elastin than collagen to cause the decrease in the slack length of collagen. It has been reported that flow-induced arterial enlargement accompanied gaps or large holes in the internal elastic lamina ${ }^{(6)}$. This may clearly indicate the increase in the unstressed length or the decrease in the elastic recoil of elastin. The decrease in the physiological strain might indicate that stress but not strain is regulated in the circumferential direction in the artery wall.

\subsection{Anisotropy in the dimensional changes}

The increase in the unstressed length took place not only the circumferential direction $\left(d_{m}\right)$ but also in the radial $(h)$ and longitudinal $(l)$ directions (Table 1). However, the change in the longitudinal direction was different from that in other two directions (Fig. 3). The increase in the longitudinal length did not have significant correlation with the increase in the wall volume. Similarly, neither stress nor strain was maintained within a constant range in the longitudinal direction in hypertensive rat aorta ${ }^{(8)}$. Changes in the longitudinal direction might be poorly regulated.

\section{4 Limitations and future study}

There are some limitations to this study. We have examined specimens exposed to high flow only for 4 weeks. Time course changes of blood vessel wall mechanical properties should be observed. Blood flow increase was too large for blood vessels to compensate wall shear stress increase. It would be interesting to study the flowinduced responses in an experimental model with moderate flow increase to know more physiological responses in the blood vessel wall. As a future study, we should study the cause of the changes in the mechanical properties. For this purpose, we need to observe histological changes in the artery wall, especially in the media. And also, we need to examine the residual stress in the wall, especially at a microscopic level. Recently, we found that residual stresses still resided even in a plate-like segment of aorta at a microscopic level ${ }^{(17),(18)}$. By measuring residual stress in the smooth muscle and elastic layers separately, we may be able to know the cause of the changes in the mechanical properties in more detail.

\section{Acknowledgment}

We thank Dr. Masato Takahashi at Akita University and Mr. Yoshiki Ogawara at Tohoku University for their superb technical assistance.

\section{References}

( 1 ) Wolinsky, H., Long-Term Effects of Hypertension on the Rat Aortic Wall and Their Relation to Concurrent Aging Changes, Circ. Res., Vol.30 (1972), pp.301-309.

( 2 ) Vaishnav, R.N., Vossoughi, J., Patel, D.J., Cothran, L.N., Coleman, B.R. and Ison-Franklin, E.L., Effect of Hypertension on Elasticity and Geometry of Aortic Tissue from Dogs, ASME J. Biomech. Engng., Vol.112 (1990), pp.70-74.

( 3 ) Matsumoto, T. and Hayashi, K., Mechanical and Dimensional Adaptation of Rat Aorta to Hypertension, ASME J. Biomech. Engng., Vol.116, No.3 (1994), pp.278-283.

( 4 ) Ene-Iordache, B., Mosconi, L., Antiga, L., Bruno, S., Anghileri, A., Remuzzi, G. and Remuzzi, A., Radial Artery Remodeling in Response to Shear Stress Increase within Arteriovenous Fistula for Hemodialysis Access, Endothelium, Vol.10, No.2 (2003), pp.95-102.

( 5 ) Kamiya, A. and Togawa, T., Adaptive Regulation of Wall Shear Stress to Flow Change in the Canine Carotid Artery, Am. J. Physiol., Vol.239 (1980), pp.H14-H21.

( 6 ) Masuda, H., Zhuang, Y.-J., Singh, T.M., Kawamura, K., Murakami, M., Zarins, C.K. and Glagov, S., Adaptive Remodeling of Internal Elastic Lamina and Endothelial Lining during Flow-Induced Arterial Enlargement, Arterioscler. Thromb. Vasc. Biol., Vol.19 (1999), pp.2298-2307.

( 7 ) Berry, C. and Greenwald, S., Effects of Hypertension on the Static Mechanical Properties and Chemical Composition of the Rat Aorta, Cardiovasc. Res., Vol.10 (1976), pp.437-451.

( 8 ) Matsumoto, T. and Hayashi, K., Analysis of Stress and Strain Distributions in Hypertensive and Normoten- 
sive Rat Aorta Considering Residual Strain, ASME J. Biomech. Engng., Vol.118, No.2 (1996), pp.62-73.

( 9 ) Fridez, P., Zulliger, M., Bobard, F., Montorzi, G., Miyazaki, H., Hayashi, K. and Stergiopulos, N., Geometrical, Functional, and Histomorphometric Adaptation of Rat Carotid Artery in Induced Hypertension, J. Biomech., Vol.36, No.5 (2003), pp.671-680.

(10) Makino, A., Kakoi, D., Miyazaki, H. and Hayashi, K., Biomechanical Response of Arterial Wall to Simultaneously Increased Blood Pressure and Flow, Proc. of Annual meeting of JSME, (1999), pp.319-320.

(11) Saito, M., Terui, N., Numao, Y. and Kumada, M., Absence of Sustained Hypertension in SinoaorticDenervated Rabbits, American Journal of Physiology: Heart and Circulatory Physiology, Vol.251 (1986), pp.H742-747.

(12) Matsumoto, T., Tsuchida, M. and Sato, M., Change in Intramural Strain Distribution in Rat Aorta Due to Smooth Muscle Contraction and Relaxation, American Journal of Physiology: Heart and Circulatory Physiology, Vol.271 (1996), pp.H1711-1716.

(13) Peterson, L., Jensen, R. and Parnell, R., Mechanical
Properties of Arteries in Vivo, Circ. Res., Vol.8 (1960), pp.622-639.

(14) Hudetz, A., Incremental Elastic Modulus for Orthotropic Incompressible Arteries, J. Biomech., Vol.12 (1979), pp.651-655.

(15) Matsumoto, T., Okumura, E., Miura, Y. and Sato, M., Mechanical and Dimensional Adaptation of Rabbit Carotid Artery Cultured in Vitro, Medical \& Biological Engineering \& Computing, Vol.37, No.2 (1999), pp.252-256.

(16) Whitemore, R.L., Rheology of the Circulation, (1968), Pergamon Press, Oxford.

(17) Matsumoto, T., Goto, T., Furukawa, T. and Sato, M., Residual Stress and Strain in the Lamellar Unit of the Porcine Aorta: Experiment and Analysis, J. Biomech., Vol.37, No.6 (2004), pp.807-815.

(18) Matsumoto, T., Goto, T. and Sato, M., Microscopic Residual Stress Caused by the Mechanical Heterogeneity in the Lamellar Unit of the Porcine Thoracic Aortic Wall, JSME Int. J., Ser. A, Vol.47, No.3 (2004), pp.341-348. 